\title{
The Creative Thinking and Feasible Way to Enhance Implicit Moral Education Efficacy in Colleges
}

\author{
Li Yajuan \\ Xi'an International University, Department of Teaching and Scientific Research of Ideological and \\ Political Theory Course, Shaanxi, xian,70077,china \\ liyajuan@xaiu.edu.cn
}

Keywords: Creative Thinking, Feasible Way, Implicit Moral Education, Efficacy, Colleges

\begin{abstract}
Implicit moral education refers to in the corresponding mechanism, all educators use a variety of resources to target moral education into the path of moral environment, functions, activities, and take the ways such as latent content, circuitous teaching, independent feel and so on, so that students exposure to specific educational context and they are pleasure to complete the process of moral education model. It is the education system consisted by the implementation subject, students, related resources, basic path, teaching methods, operating mechanism. There are three ways to enhance the effectiveness of the implicit moral: clear the performance of the features, innovative thinking and the feasible way.
\end{abstract}

\section{The Factors Affecting the Effectiveness of Implicit Moral Education}

Factors affecting the effectiveness of implicit moral education are mainly subject, object and environment.

The principal factors included educational objectives, educational content, educational mode, educational system and educational ability. Educational goals is reasonable, whether the appropriate educational content, educational model is valid, whether supporting the education system, educational capacity is in place, will more or less affect the effectiveness of the implicit moral education. Which affect the ability of education more critical, because various other substantially determined by the ability of education.

Object factors contain a demand factor intention, character level, mental state, personality differences. The main intention is to demand that students receive education preferences, such as the content, the way, the path of recognition; character level mainly refers to the level of students 'moral behavior, such as moral values, codes of conduct; mainly refers to the psychological state of students' mental health level, such as positive or decadent downturn; personality differences mainly refers to the tendency of students personality type, such as cheerful sociable or withdrawn autistic like. Where demand factors intention is relatively important, because if the content of education, methods and paths cannot attract students resonance, it is difficult to produce the desired effect.

Environmental factors included campus atmosphere, family background, social environment. Family background, such as whether there is the right tutor, harmonious relations;; campus atmosphere, such as The school appearance, faculty model, teacher-student relations, social environment, such as the development trend of the times, leading to the idea and so on. Among them, the factors campus atmosphere more realistic, because the campus is the base for student learning and life, student learning and campus life experience and atmosphere are closely related.

\section{The Creative Thinking to Enhance Implicit Moral Education Efficacy in Colleges}

The idea of educating people. Philosophy is a prerequisite for quality, with the right idea, will have a corresponding behavior. Enhance the quality of university workers and we must start from the updated concept. The idea of educating people showed educational philosophy, students view and the viewpoint of the times. From education to watch, you need to have people-centered education, moral education as the most important showcase for the first concept, we should take the responsibility of 
educating people to moral education as the core, to demonstrate oriented, full of educating people to work to implement in their posts on, throughout their operations. Viewed from the students, need to have the focus on the development, approval status, the concept of respect for individuality, should pay attention to the development and changes of students, recognition of the dominant position of students, understanding students' individual needs, make educating people work more structured, interactive and targeted . From the age view, the need to follow the development of the concept, with the education service, students are customers, focusing on the transformation of consciousness, to severe, teach, managed care educators to inspire, guide-type transition from educators.

Take the students' needs as the focus. Object educational services students, colleges and universities to improve the quality of workers and we must focus on the needs of students, and student demand-oriented. Implicit moral status of the aforementioned survey, college students practice the words and deeds, to change the mode of education, to strengthen teacher-student interaction demands, as well as relevant studies show that students of university workers role expectations, should become universities improve the quality of workers basis [1] .

Take the quality of the subject as a starting point. Quality is the basis of efficiency, improve performance must start with improving quality. In addition to considering the needs of students, colleges and universities need more management features according to the requirements of the law of occupation, job responsibilities, education, age, targeted to enhance the quality of University workers, such as professional awareness of the teacher, the professional capability The pragmatic and personality traits of character improvement, and through their good professional awareness, professional competence and personality traits of the show, on the growth of the students play a subtle role.

Use the self-discipline environment. Improve the quality of workers in universities, is inseparable from self-discipline environment. Build self-discipline environment, you must complete a two-pronged external and internal constraints. External constraints, mainly through institutions and mechanisms employed by the system to clear the bottom line, so that every staff understand their responsibilities and conduct regulatory requirements; and establish enforcement mechanisms will study the system illegal, let teachers institutional framework and mechanisms completed within the requirements of self-discipline. The inherent perfect is mainly through self-learning, self-reflection and self-regulation to achieve. Self-improvement is a gradual process of self-discipline through self-learning, self-reflection, self-regulation of the cycle, can promote the continuous optimization of University Teachers' Professional ideas and behavior.

\section{The Possible Ways to Enhance the Implicit Moral Education Efficacy in Colleges}

Improve access mechanism. The access mechanism includes eligibility and level two levels. Although China has been Teacher system, but relative to foreign universities, there is still a gap in the teacher employment rigor. In the United States and Germany, for instance, university teachers recruitment usually publish information on the mainstream media, clear job recruitment, conditions, treatment and procedures, both at home and abroad that they meet the conditions can apply; and for teachers working requirements high, such as to have a doctorate and related research or work experience and so on [2].

Improve the training system capabilities. Training system is mainly to improve the capacity, through training so that serving teachers qualified their work. Training mechanisms includes regulations, systems and models three connotations. At present, China's teacher training, in terms of regulations, systems and patterns there are many problems. The first is the introduction of appropriate legislation yet; followed by the training system has not been included in the track; again is a lack of effective model. The foreign experience in this regard, there are many worthy of our reference, such as France and the United Kingdom respectively provide university teachers in five to seven years can leave a month for further study; America's "future teacher training programs," so that by participating in the $\mathrm{PhD}$ cooperative school teachers work in advance of its responsibilities section. 
Safeguard the interests of the protection mechanism. Security mechanisms include both material and spiritual aspects. Material security is mainly reflected in the remuneration, security is mainly reflected in the spirit of respect. Both compared with foreign countries, China also has a greater difference. From material security, the teachers of universities France, Britain, Japan and other countries are included in the Civil series; German university teachers salaries significantly higher than in other occupations; American College teachers' salaries are 2.3 times the national average wage to 4.8 times. In China, state-owned education sector employees in 2009, the average wage level is only ranked No. 10 in all 19 industries. From the spiritual security, the French clearly defined in the Board of Directors, the Academic Committee is responsible for the University leadership and management, life learning university committee, the representatives of the teachers and staff to account for $30 \%$ to $60 \%$, respectively. Many countries also expressly provides for the guarantee of academic freedom of university teachers, such as the German state university laws provide university teachers can not be penalized because of the teaching content; the provisions of the American College Teachers have the right to all kinds of problems they face complaints and requests hearing, the school offers a variety of specialized body to deal with complaints of teachers, in order to protect the legitimate rights and interests of teachers [3].

Elimination mechanism to improve the team. Elimination mechanism is to improve the team, in order to improve the overall quality of University Workers and increase the competitiveness of university development. Elimination mechanism including the establishment of the system, strict management and provide a way out 3 content. There are many foreign practices worth learning, such as teachers into American universities professors, associate professors, assistant professors three categories, there is a rigorous selection and review process, evaluation criteria not "one size fits all" or emphasize academic achievement or pay attention to the quality and effectiveness of teaching , meet the requirements necessary to find another way out. France to implement "non-liter-go" policy, university teachers not promoted when the term of office expires or must leave school dismissal. In addition to promotion evaluation, foreign universities are also very focused on the quality of teachers' work and evaluation, examination results directly linked with reward and punishment lift. Universities also clear job classification system abroad, according to the degree of responsibility, work difficulty, qualification level consistent with a number of jobs into rank, treatment and rank. Out of the system at the same time establishing foreign universities very focused on social employment resource use, such as unemployment insurance and job market, in order to ensure that university teachers in the corresponding period to find another way to protect the lives and opportunities for re-employment.

The use of the method Using the analysis to focus on a clear direction. Key analysis emphasized prioritizing, will manage the object is divided into A, B, C three types, A class is the focus of management, is the second priority class B, class $C$ is general. Introduced in teacher quality management focused analysis, management can make more clear direction, more focused, more improved efficiency. Due to the different management objects, in the implementation of key analysis also need to make appropriate adjustments and modifications. Quality of University workers are difficult to quantify, so you can measure the degree of attention as an important indicator of the degree, the relevant data can be obtained by the students in investigation methods, the quality of variable Universities workers should be divided into different dimensions (such as professional awareness, professional knowledge, etc.) and level (eg occupational consciousness teacher, care for students, etc.) and use statistical tools (such as social science statistics program SPSS) a summary of the survey results, through systematic analysis of the questionnaire, draw the appropriate option in descending score order, and is divided into A, B, C categories. For Category A projects to be the focus of management, and strive to achieve tangible results; for $B$ class project management to be appropriate to ensure that no problems; on the $C$ class project management can be relaxed, mainly rely on self-discipline [4].

Management by objectives to promote the use of the process. The main characteristics of the target management method is to determine the upper and lower common goals down to every level to the people, the implementation of the control objectives. Out on the implementation of management by 
objectives approach is not, the main problem is quantitative indicators, because the difficulty of quantitative indicators will be significantly higher than the quality of management of enterprise management. Therefore, when a variety of indicators to quantify the process should use SMART principle, the implementation of "specificity" "measurability" "can be realized" "reality" "time-bound " criteria to ensure that the set of measurable indicators. In doing the work on the basis of quantitative indicators to regularly assess the achievement of goals assessment, lessons learned rewards and punishments, and constantly promote goals.

Use the stress management methods to resolve conflicts. Stress management is more successful EAP (Employee Assistance Program) mode. EAP model has characteristics as professional, persistent, systematic, welfare, by helping employees solve psychological and behavioral problems, to achieve the purpose of improving the organizational climate and management efficiency. EAP mode in colleges and universities in the United States has been widely used, usually the diagnosis by the pressure, promotion, improving the environment, education and training, psychological counseling and other five planes form.

Cyclic Improvement Act to consolidate the results. Improvements Act cycle including planning (Plan), implementation (Do), checking (Check) and propulsion (Action) 4 contents. With the promotion and practice of recycling laws, its applications continue to expand, as long as the cycle time and improve the relevance of the work, are included in the scope robin management. Quality management is also a need to improve the circulation and rising job, so by circulating Improvement Act to consolidate the effect of the quality of the management of colleges and universities were wise choice. Improvements Act implementation cycle typically includes find the problem, check the reason, the main reason given, to plan, implement and promote, weight check, grasping norms, recycle eight steps. Universities can on the status of analysis to identify issues affecting the quality of universities and the main reason for workers to develop and implement appropriate plans, regular

assessment, identify problems, lessons learned, while the issue is not resolved or transferred to the new emerging a loop to solve [5].

\section{Conclusion}

In short, on the basis of clear the effectiveness of the elements, we should enhance the quality of workers in universities and through a sound mechanism and use the feasible ways, the implicit moral education effectiveness can be effectively improved.

\section{References}

[1] F.Q.Deng, The thoughts on ideological and political education humanistic value orientation, J. Ideological Theoretical Education. 18 (2009) 53-59.

[2] X.L.Bai, The distinctive character of recessive ideological and political education, J. School Party and Ideological Education. 9 (2007) 32-36.

[3] X.L.Bai, The process of implicit ideological and political education, J. Ideological Theoretical Education, 32(2012) 189-190.

[4] Y.J.Qi, The concept positioning of recessive ideological and political education, J, School Party and Ideological Education, 4(2007) 38-40.

[5] D.S.Zeng, The new trends in contemporary political education, J. Ideological Theoretical Education, 9(2010) 142-150. 